\title{
A UNIVERSIDADE BRASIIEIRA E A REFORMA ATUAL
}

\section{The Brazilian University and in Progress Current Reformation}

\author{
Elizabeth M. Aguiar Pereira ${ }^{1}$
}

\section{Resumo}

Uma das afirmações explicitadas no texto da Exposição de Motivos da terceira versão do Anteprojeto da Reforma (julho, 2005), é a de que a educação superior é um bem público. Isso supostamente seria um princípio que acarretaria, necessariamente, posturas diferenciadas em relação aos currículos e aos ditames do modelo neoliberal de gerir a educação superior, que vem sendo implementado nas últimas décadas. $\mathrm{O}$ anteprojeto explicita que a educação superior não é mercadoria, mas um bem público que consolida um novo modelo de desenvolvimento para o país (MEC, 2005). Como proposição, é alvissareira essa afirmação, mas no Brasil, muitas vezes o que está aparentemente proposto não é bem o que está subentendido nem o que será efetivado, a espera pela transformação do anteprojeto em lei e pela sua implementação, representam um período crucial de compasso para a universidade brasileira. $\mathrm{O}$ anteprojeto de lei pretende estabelecer novas normas para a educação superior, e para isso, revoga todo o Capítulo IV da LDB (do art. 44 a 57) que se refere à Educação Superior e altera artigos de legislações de 1994 a 2002, introduzidas no período democrático. É interessante apontar que a revogação da lei 5.540/68, promulgada no período ditatorial, já havia sido revogada pelo art. 92 da LDB (lei n.o 9394/96).

Palavras-chave: Política do ensino superior brasileiro; Gestão da educação superior, Reforma universitária.

1 Docente e Pesquisadora da FE da UNICAMP. Coordenadora do Grupo de Estudos e Pesquisas em Ensino Superior da Faculdade de Educação da UNICAMP. E-mail: eaguiar@unicamp.br 


\section{Abstract}

One of the affirmations explicitadas in the text of the Exposition of Reasons of the third version of the First draft of the Reformation (July, 2005), is of that the superior education is a good publishes. This supposedly would be a principle that it would cause, necessarily, positions differentiated in relation to the resumes and the neoliberal model to manage the superior education, that comes being implemented in the last decades. The first draft, that the superior education is not merchandise, but public good that consolidates a new model of development for the country. (MEC, 2005). As proposal this affirmation is possess intention education's but in Brazil, many times what pparently it is considered, are not well what he is implied nor what will be accomplished, the wait for the transformation of the first draft in law and for its implementation, represents a crucial period of compass for the Brazilian university. The draft bill intends to establish new norms for the superior education, and for this, it revokes Chapter IV of the LDB all (of art. 44 the 57) that it is mentioned to the Superior Education and it modifies articles of laws of 1994 the 2002, introduced in the democratic period. It is interesting to point that the revocation of law 5,540/68, promulgated in the totalitarianism period, already law had been revoked for art. 92 of the LDB (no. 9394/96).

Keywords: Politics of brazilian's educations; Management of the academic education; The university reformation.

Vivemos atualmente a expectativa da transformação em lei da terceira versão do anteprojeto da reforma universitária do governo de Luis Inácio Lula da Silva. Desde o final de 2003, o governo brasileiro vem trabalhando na proposição de uma "reforma universitária, para adequá-la às exigências dos tempos atuais" (MEC, 2005, p. 1). Seus princípios e objetivos já são conhecidos e foram postos para discussão desde a primeira versão de seu anteprojeto. Embora tenha sofrido várias alterações, tem conservado a direção e a finalidade que a fomentaram. Uma rápida discussão sobre os seus propósitos para a educação superior e, notadamente, para a instituição universidade se faz necessária para que possamos compreender o processo de estruturação/desestruturação a que estarão submetidos as instituições, os currículos de curso e a formação dos alunos.

Uma das afirmações explicitadas no texto da Exposição de Motivos da terceira versão do Anteprojeto da Reforma (julho, 2005) é a de que a educação superior é um bem público. Isso supostamente seria um princípio que acarretaria, necessariamente, posturas diferenciadas em relação aos currículos e aos ditames do modelo neoliberal de gerir a educação superior, que vem sendo implementado nas últimas décadas. 0 anteprojeto explicita que a educação superior não é mercadoria, mas um 
bem público que consolida um novo modelo de desenvolvimento para o país (MEC, 2005). Como proposição é alvissareira essa afirmação, mas no Brasil, muitas vezes o que está aparentemente proposto não é bem o que está subentendido nem o que será efetivado. A espera pela transformação do anteprojeto em lei e pela sua implementação representam um perío do crucial de compasso para a universidade brasileira.

$\mathrm{O}$ anteprojeto de lei pretende estabelecer novas normas para a educação superior, e para isso, revoga to do o Capítulo IV da LDB (do art. 44 a 57) que se refere à Educação Superior e altera artigos de legislações de 1994 a 2002, introduzidas no período democrático. É interessante apontar que a revogação da lei 5.540/68, promulgada no período ditatorial, já havia sido revogada pelo art. 92 da LDB (lei n.o 9394/96).

Entre os educadores brasileiros, alguns manifestaram apoio irrestrito às proposições governamentais do anteprojeto, defendendo, inclusive, sua implementação imediata por meio de Medida Provisória. Outros foram profundamente críticos, afirmando que a reforma implicaria em "piora" imediata das condições - já precárias - de funcionamento das universidades públicas, principalmente as federais, chegando algumas dessas críticas a classificar a iniciativa governamental como tipicamente neoliberal e como uma imposição do Banco Mundial e do FMI (MANCEBO, 2004; DOURADO; CATANI; OLIVEIRA, 2005).

Na exposição de motivos, o então Ministro da Educação Tarso Genro $^{2}$ aponta que democratização, qualificação das instituições de ensino superior e eqüidade são objetivos centrais do anteprojeto - "Atualmente, o grande desafio é o de construir um sistema de educação superior que realize o equilíbrio entre qualidade acadêmica e compromisso social" (p. 4). Destaca-se no documento a afirmação de que a educação superior está desafiada a exercer um papel de liderança na construção de um novo projeto nacional, uma vez que o Brasil aspira ocupar lugar valorizado na divisão internacional do conhecimento.

Nesse sentido, as orientações desse anteprojeto são ditas estarem baseadas nos grandes problemas da nação, tais como: a superação das desigualdades sociais, a construção de um modelo de desenvolvimento sustentável, o crescimento econômico com justiça social e equilíbrio ambiental. Explicitamente é dito que:

2 É interessante mencionar que coincidentemente as duas reformas da educação superior foram propostas por Ministros da Educação com o nome de Tarso. O anteprojeto da Reforma de 1968, que se transformou na Lei $n . \stackrel{0}{5540 / 68}$ foi presidido pelo Ministro Tarso Dutra e esta agora pelo Ministro Tarso Genro. 
As instituições de ensino superior, e as universidades em particular, portanto, devem ser pensadas em conexão com os grandes impasses e dilemas que deverão ser superados pelo Brasil nas próximas décadas, entre os quais se sobressaem a superação das desigualdades e a construção de um modelo de desenvolvimento sustentável, capaz de conciliar crescimento econômico com justiça social e equilíbrio ambiental (MEC, 2005, p.1).

O princípio da democratização é tido pelos reformadores como o princípio que tem a preocupação de fazer a educação superior chegar às camadas mais pobres. Para isso, a reforma prevê, além do aumento da oferta de vagas e da criação de novas instituições, uma proposta de inclusão que pretende ser o aspecto mais importante da reforma. A implementação dessa medida é pela reserva de $50 \%$ das vagas atualmente existentes no ensino público, para alunos oriundos do ensino médio público e, dentro desta porcentagem, uma parte deverá ser destinada a estudantes negros ${ }^{3}$ e indígenas de acordo com a participação dessas populações em cada estado (Instituto Brasileiro de Geografia e Estatística - IBGE).

Embora essa discussão passe pelo princípio da democratização das vagas do ensino superior, a história das universidades medievais Verger (1990) demonstra que no período em que essas instituições foram organizadas por "nações de estudantes" formando corporativismos ditados pelos privilégios que eles se impunham, um destes privilégios foi o de anular toda e qualquer possibilidade de seleção por mérito. A seleção por mérito foi uma conquista de lutas democráticas do período medieval e assinalou a abertura das portas da universidade a estudantes capazes, independente de sua origem social. Como nessa época a origem social dos estudantes era a dos nobres e famílias abastadas, a seleção por mérito representou a vitória do valor democrático na organização das universidades.

A reserva de vagas intencionada e já implementada por algumas universidades volta a estabelecer o privilégio mesmo que seu argumento seja a classe menos favorecida. A universidade vai voltar a ser uma instituição de privilégios, embora para muitos defensores essa seja a hora tardia do privilégio para as classes menos favorecidas. Podemos dizer que este é um projeto "medieval" às avessas, onde muda a clientela (privilégio da classe pobre) e 0 poder instituído (do poder papal ou imperial ao poder do populismo). Apresentada como um aspecto relevante da democratização do ensino público, essa proposta tem oponentes e simpatizantes.

Incluindo-me como uma dos que fazem a crítica sobre o pouco alcance democrático que esta proposta de fato representa, vejo que a visão de

3 Atualmente 15 universidades brasileiras já oferecem o sistema de cotas para afro-descendentes, sendo oito instituições estaduais e sete federais. 
ação afirmativa que ela traz pouco se sustenta como ação efetiva de inclusão. Uma primeira questão é a de que a proposta não leva em conta que, na maioria das universidades federais, a porcentagem de alunos vindos da escola pública é próxima dessa porcentagem como demonstram os dados do INEP/ 2006, onde 42,2\% dos estudantes nas Instituições Federais de educação superior são oriundos das escolas públicas e $45,9 \%$, das privadas. A diferença entre as porcentagens não são tão acentuadas quanto os discursos apregoam e não se alterará substancialmente como a medida tem sido vendida na mídia. As porcentagens de estudantes nas instituições públicas dos estados do Norte e Nordeste do país, oriundos da escola básica pública são superiores a 50\%. Com isso, a medida terá mais impacto nos estados do Sul e Sudeste.

A segunda questão é a prática bem brasileira de não se criar nada que aumente os "gastos" do Estado com educação e assim, o que se apresenta como uma importante ação social é, no fundo, uma esdrúxula política educacional, pois retira $50 \%$ das já insuficientes vagas públicas para reservá-las à nova clientela, em vez de criar mais $50 \%$ de novas vagas, em todo o ensino público superior, para esta reserva. A proposta representa um passo para um pré-conceito invertido, onde os alunos que não fizeram toda a educação básica no ensino público serão vistos como "ocupando" as vagas que poderiam ser destinadas aos mais pobres. Sendo alunos de melhor poder aquisitivo, sua destinação natural deveria ser as instituições privadas. O discurso de que as universidades públicas são freqüentadas majoritariamente por alunos de classe privilegiada passou, por si mesmo, a ser uma verdade não obstante as estatísticas provarem a falsidade da afirmação. É sob esse véu que a medida da reserva de vagas está se estabelecendo.

Os dados do Censo da Educação Superior de 2004 demonstrando que 26,5\% dos alunos nas IES públicas têm renda familiar de até três salários mínimos, enquanto essa porcentagem é de 12,9\% nas IES privadas e que a porcentagem de alunos com renda familiar maior que dez salários mínimos é de $29 \%$ nas IES públicas e $41,6 \%$ nas privadas, torna mais difícil a argumentação do discurso da "boa escola pública para a classe privilegiada e da má escola privada para a classe pobre".

A terceira questão é a reserva de vagas para a inclusão das minorias raciais. Da forma como a proposição está argumentada, ela tende a tratar as desigualdades sociais como uma questão racial e não como uma questão econômica. Para o anteprojeto, o câmpus universitário não reflete a "cor da sociedade" e não apresenta um equilíbrio com as porcentagens de brancos, negros e pardos da população brasileira ${ }^{4}$. Assim, sendo que a porcentagem de

4 Segundo a Exposição de Motivos (p. 26), os dados do IBGE apontam que os brancos na sociedade somam $52 \%$ e no câmpus $72,9 \%$; os negros somam $5,9 \%$ e no câmpus $3,6 \%$ e os pardos $41 \%$ e $20,5 \%$ no câmpus. 
brancos é significativamente maior que a negra e a parda, há, para a proposta, uma clara exclusão discriminatória no ensino superior. Essa conclusão é simplista bem como a proposta para reverter esse quadro, pois a exclusão tem se dado não por um problema racial, mas por uma questão econômica e de acesso à educação básica. A proposta do anteprojeto pretende que a correção da ausência de alunos de poder aquisitivo mais baixo no cenário universitário, problema que deve ser trabalhado desde o ensino fundamental, seja uma responsabilidade do ensino superior. Está implícita nessa visão que a ascensão social é intimamente relacionada à freqüência ao ensino superior, quer para os mais pobres, como para as minorias étnicas. Nada mais falso, como Bil Gates, Lula e inúmeros industriais, empresários, políticos, cantores, esportistas, estão aí para provar.

Ainda como meta de democratização do ensino superior, o governo está implementando, desde 2005, o programa "Universidade para Todos" ProUni, que pretende viabilizar o ingresso, até 2010, de 300 mil novos alunos de baixa renda, oriundos da educação básica pública, em vagas abertas pelas instituições privadas. Estes alunos receberão, dessas instituições, bolsas integrais ou parciais distribuídas conforme o perfil socioeconômico. A seleção para ingresso nessas instituições será por meio da nota do Exame Nacional do Ensino Médio (ENEM).

Segundo dados do MEC (2005), no primeiro ano do ProUni, as 1.142 instituições privadas de todo o país ofereceram 112. 275 mil vagas, das quais 47 mil foram reservadas para estudantes negros e indígenas. Das vagas oferecidas, 107.477 foram ocupadas. O MEC informa ainda que com essa medida houve um acréscimo de 5\% no número de estudantes negros nas instituições de ensino superior. No primeiro semestre de 2006, o número de instituições aumentou para 1.388 e as vagas oferecidas foram de 91.609 , das quais 90.538 foram ocupadas. Sendo a contrapartida a que as instituições privadas estão obrigadas, bastante vantajosas para elas, a aceitação e a abertura de vagas oferecidas foi maior que a matrícula dos alunos, tanto no ano de 2005 como no primeiro semestre de 2006.

O programa de criação de bolsas é na visão do MEC (2005, p. 35) "uma das formas mais baratas de promover o acesso ao ensino superior. Cada vaga no ProUni custa ao governo o equivalente a 25\% de uma vaga oferecida pelo Fies ${ }^{5}$ (Fundo de Financiamento ao Estudante de Ensino Superior". Para equacionar a ampliação do acesso ao ensino superior sem maiores investimentos, o Estado, tendo como parâmetro a sua incapacidade de garantir edu-

O Fies continuará a financiar alunos que não se enquadram nos critérios de seleção do ProUni. Segundo dados do MEC (1005), em 2005 foram destinados R\$ 829 milhões para o Fies, em 1.370 instituições de ensino superior privadas e beneficiados 235740 alunos. 
cação conforme as exigências da demanda, optou por "parcerias" com as instituições privadas, tornando-as atores privados com fins públicos. O que estamos assistindo é que estas políticas de inclusão não estão estimulando, nem resultando, em maiores aportes de recursos financeiros e de pessoal, que contribuam para reverter o quadro de baixa qualidade da educação superior e que possam oferecer uma formação universitária adequada a padrões considerados de qualidade.

Podemos especular que a implementação desse programa, sem estar o anteprojeto da Reforma votado no Congresso, faz parte de uma estratégia governamental de "fatiar" a sua implementação, tendo em vista as dificuldades que tem encontrado no Congresso para a aprovação de muitos de seus projetos.

Uma das propostas que podemos dizer que vem ao encontro das lutas por aumento da oferta das vagas públicas é a da expansão das ofertas do sistema público, que tem como meta atingir $40 \%$ do total de matrículas, até o ano de 2011. É prevista a expansão de instituições federais com a criação de três novas universidades e 32 novos campi, e a geração de 300 mil novas matrículas nos cursos de graduação, mestrado, doutorado e extensão. Podemos dizer que em tempos neoliberais, essa é uma proposta ousada. No entanto, as formas de financiar essa expansão causam preocupação, uma vez que a prioridade do governo tem sido o ajuste fiscal a qual levou as políticas sociais a serem relegadas e transformadas em programas assistenciais de impacto.

Sabemos que a reforma, para contribuir com as possibilidades de 0 ensino superior cumprir com as metas do Plano Nacional de Educação, precisará implementar políticas que dobrem, em seis anos, o número de estudantes nas instituições superiores.

Outro princípio que apontamos como bastante favorável é o que prevê recursos e autonomia financeira às instituições federais. Para consolidar essa política, está previsto no anteprojeto que a União aplicará, anualmente, nas instituições federais de ensino superior, nunca menos de $75 \%$ da receita constitucionalmente vinculada à manutenção e ao desenvolvimento do ensino. É previsto ainda que as instituições poderão usar seus recursos de acordo com um planejamento próprio, o que acabaria com o engessamento da gestão financeira das IES Federais.

As análises que podemos fazer das proposições do anteprojeto não escondem que esta também está embasada em uma preocupação de acompanhar as mudanças econômicas estruturais do mundo globalizado e as demandas do capital produtivo e que suas proposições não se diferenciam daquelas desenvolvidas nos últimos dez anos, especificamente na reconfiguração das esferas pública e privada. 
Sabemos que o quadro atual da expansão do ensino superior privado é resultante de uma política de décadas de descompromisso do Estado e por intencionalmente delegar ao setor privado a condição de ocupar esse espaço, inclusive com uma frágil regulação do Estado. Hoje, essa situação resulta num quadro onde $71 \%$ das vagas do ensino superior são oferecidas pela rede privada e $29 \%$ pela pública (MEC, 2005).

Acreditamos que a reforma, que tem por pretensão solucionar problemas há muito apontados pelos movimentos de professores e suas associações, e dos alunos e seus centros acadêmicos, pouco venha mudar o cenário atual por continuar a se orientar por princípios economicistas e produtivistas. Esses princípios têm como principal função da universidade a transmissão de conhecimentos utilitários para uma economia de mercado, a sua vinculação com as necessidades imediatas da sociedade e o atendimento ao contexto local e regional.

Buscando mapear o entendimento que o anteprojeto tem de universidade e o equacionamento da expansão do ensino privado, podemos apontar que neste, a universidade passa a ser uma instituição responsável por justificar-se ao povo que, segundo as defesas mais engajadas, é quem paga a universidade com seus impostos e, por isso, é a ele que esta tem de se voltar. Com isso, a universidade deve se explicar a seus "pagadores", prestar-lhes "serviços" de forma explícita e não só como produtora e crítica do conhecimento. A própria produção de conhecimento prevista no anteprojeto tem de estar voltada para propósitos regional e/ ou local (MEC, 2005). De forma clara, o anteprojeto afirma: "As instituições de ensino superior são chamadas a interagir com as vocações e as culturas regionais, repartindo o saber e a tecnologia com toda a sociedade. Os recursos instalados pelas universidades e, particularmente, os conhecimentos que ali são gerados,constituem um patrimônio de todos os brasileiros e uma das razões de nosso orgulho como nação" (p. 1).

A afirmação contém em si mesma a contradição entre 0 alto valor da universidade e o que deve ser a sua contribuição quando propõe que esta interaja com as vocações e cultura regionais. Ao mesmo tempo, reconhece que os conhecimentos gerados por ela é patrimônio de todos os brasileiros. A universidade, sendo uma instituição que tem como característica estar ao mesmo tempo localizada em seu tempo histórico e a frente dele, inserida em uma sociedade mas não presa a ela, atende ao princípio democrático de beneficiar as atividades humanas, quer locais, regionais, nacionais ou universais.

Nesse sentido, Newman (2001, p. 150), em seu livro "A idéia de uma universidade", na defesa da universidade como aristocracia intelectual diz "uma universidade é o alto poder protetor de todo o conhecimento e ciência, de fato e princípio, de investigação e descoberta, de experiência e especulação; ela mapeia o território do intelecto e vela para que não haja nem invasão nem 
rendição em nenhum dos lados". No entanto, o anteprojeto, ao dar uma ênfase mais acentuada à função de compromisso social da universidade e afirmar que a reforma "direciona-se a uma nova política capaz de refundar a missão pública dos sistemas de educação superior" (Anteprojeto, p. 10), entende que a educação superior deva responder às demandas das "instâncias representativas da sociedade". Esta é uma forma mais restrita de entender a "missão" da universidade, pois a vincula com determinadas instâncias sociais.

É a contradição entre o projeto de formar um indivíduo livre como o queria Newman (2001) e o de vê-la como um fator de mobilidade e promoção social. Essa contradição é antiga e vem sempre ligada a um projeto que, na idade Média, previa que um homem de classe pobre podia ascender a postos na hierarquia eclesiástica se cumprisse programa de estudos superiores e obedecesse às suas determinações. Dessa forma teria ele adquirido a cultura clerical necessária e atestada pelo diploma da universidade. Mais tarde, o sistema capitalista, notadamente no século XIX, fez uso da mesma vinculação para controlar o poder de sua hierarquia e conceder status à pequena corporação de "habilitados" conferido pelo valor do diploma. Cada vez mais o sistema solicita diploma a atividades profissionais numa clara intenção de restringir 0 acesso.

Flexner (1930) já nos anos de 1930 analisa que a universidade, como instituição, não deixa de estar dentro da textura social de uma determinada época e que por isso não é uma instituição isolada, que não cede às pressões, às forças, às influências de seu tempo histórico. Para ele, a universidade é, ao contrário, uma expressão da época e uma influência que opera tanto sobre o presente quanto sobre o futuro. Com essa defesa, lamentava que as universidades, já nesse tempo, estivessem se tornando apenas "escolas secundárias superiores, com preocupações vocacionais ou escolas de formação de professores e centros de pesquisas locais e até "agências de ascensão social". Lamentava profundamente que estas estavam se transformando em postos de serviços locais para o público em geral, numa equivocada visão de bem público e social.

Acreditamos que a universidade seja por si mesma uma instituição que se volte para o seu tempo histórico e para as questões da sociedade, mas restringir ou dar prioridade ao local e regional é diminuir a missão dessa instituição que, por ter como característica e saber como estar ligada ao passado, ao presente e ao futuro, não se prende em questões de curto alcance e é hoje uma das poucas instituições milenares que guarda sua identidade própria. Assumimos que a referência à cultura nacional, regional e local é um aspecto de relevância no desenvolvimento das atividades curriculares da educação superior, mas como ponto de partida e não como ponto de chegada. 
Polêmicos também são os critérios para que uma instituição de ensino superior possa manter o status jurídico de universidade e a autonomia para criar cursos e ampliar vagas sem prévia autorização do Ministério da Educação. Segundo a terceira versão do anteprojeto, ela deverá oferecer o mínimo de 8 cursos de graduação (na segunda versão eram 12), 3 de mestrados e 1 de doutorado. Como 99 das 164 universidades brasileiras hoje não atendem a essas exigências e os investimentos em pós-graduação são muito altos, elas terão o prazo de seis anos para cumprir essa determinação.

Na prática, o que o governo está pretendendo fazer com essa iniciativa é promover uma expansão quantitativa de mestrados e doutorados em todo o país. Com isso, o risco é o de que a pós-graduação acabe reproduzindo os mesmos problemas de qualidade que apresenta a graduação, desmoralizando o nível de pós-graduação do sistema da educação superior reconhecido como o mais qualificado da América Latina e com padrão internacional de qualidade.

De instituição reconhecida como aristocracia intelectual (e não aristocracia social) a universidade tende a se tornar uma instituição social populista, com a missão de resgatar os excluídos pelos desmandos sociais de séculos.

$\mathrm{O}$ anteprojeto da reforma ressalta que a proposição de reforma vem substituir um estatuto legal herdado do regime autoritário, referindo-se à Lei n. 5.540/68, e afirma ser esta tarefa inadiável. É interessante que essa argumentação desconsidera o artigo 92 da LDB, Lei 9294/96 atualmente em vigor, que revoga as disposições das leis do período autoritário (Leis n.. ${ }^{4}$ 4.024/61; 5.540/68; 5.692/71 e 7.044/82).

Além dessa argumentação para justificar a proposição da reforma, o anteprojeto afirma que o "sistema brasileiro está fragmentado" e que "banalizou-se 0 conceito de universidade e expandiram-se as instituições privadas com critérios frouxos de regulação e supervisão" (p. 6). Apresenta que estas são "questões centrais enfrentadas pela presente proposta de Reforma da Educação Superior" (idem). O anteprojeto aponta que a educação privada é uma função pública delegada e anuncia medidas para um maior controle de sua expansão, tentando prevenir a proliferação de instituições caça-níqueis.

Embora a forma de se referir à educação privada como "uma função pública delegada" traga um entendimento de que há uma relação com os objetivos da educação pública, não se tem notado uma parceria entre as instituições públicas e as particulares, convergentes em objetivos. A expressão numérica que essas instituições atingiram atualmente as tornou uma força educacional com poder, e o "direito" de desempenharem uma atividade de interesse público e cobrarem por ela foi conferido pela legislação educacional desde a Constituição de 1946 (CARVALHO; CAMPOS, 1991). 
Sucessivas legislações mais permissivas e a desenfreada expansão ocorrida a partir de 1960 permitiram a taxa atual de oferta da educação superior de $70 \%$ e demonstra o espaço aberto pelo tímido atendimento público, além de incentivar o investimento financeiro empresarial pela segurança de retorno com clientes ou consumidores potenciais "do produto". Essa situação é inversamente proporcional no ensino fundamental, onde a presença da educação pública é quase predominante.

Quando falamos de instituições de educação superior privada, estamos nos referindo quase que essencialmente à oferta de cursos profissionalizantes. O compromisso dessas instituições na área da pesquisa é mínimo, pois esta atividade não se faz sem instalações complexas e caras que, dificilmente, as atraem, mesmo quando as pesquisas visam demandas de curto prazo e aproveitamento mercadológico imediato.

São conhecidos os argumentos em favor da iniciativa privada, particularmente no ensino superior, passando pela condição democrática de possibilitar a escolha pelo estudante de fazer a sua formação onde melhor lhe convier, pela possibilidade de haver mais diversidade e liberdade de opções, até a defesa de que o governo deve prioritariamente investir seus recursos na educação básica, melhorando a sua eficiência e a sua qualidade. Esta forma de ver a "contribuição" da iniciativa privada tem muitos defensores. Schwartzman (2005, p. 20) diz que "Os países que mais conseguiram expandir a educação superior nos últimos anos são os que optaram por abrir espaço para o setor privado e para o ensino a distância".

O atual governo, na proposta de reforma universitária e nas políticas de educação superior já implementadas, optou por desencadear uma ação de "resgate de dívida social", abrindo vagas públicas nas instituições privadas, destinadas a estudantes carentes que, pelo péssimo ensino médio público obtido, não têm o preparo educacional adequado para competir nos processos seletivos das universidades públicas. Como estes alunos também não têm condições financeiras para arcar com as mensalidades das instituições privadas, o governo, pelo programa ProUni e por meio de renúncia fiscal, está sendo o maior credor do tipo de ensino privado, bancando a subsistência de inúmeras dessas instituições que já não tinham condições de se manterem por apresentarem uma taxa de inadimplência perto dos 50\%, embora nas análises críticas que empreende, paradoxalmente faça a crítica não deixando de considerar esse setor como um setor educacional "mercantilizado".

É interessante atentar para os dados estatísticos atuais que apontam para a porcentagem de apenas $9 \%$ da população de 18 a 24 anos estarem na educação superior. Com a medida adotada pelo ProUni, o governo não aumentou o número de vagas (e conseqüentemente a porcentagem dessa população), realmente democratizando o acesso de um maior número de jovens, 
mas preencheu as vagas privadas com maior número de alunos, "democratizando", no limite, apenas o acesso destes alunos a um ensino privado proibitivo a seus recursos financeiros.

Uma medida muito mais democrática seria o aumento de novas vagas nas instituições públicas para alunos da escola básica pública (não a divisão das já existentes), selecionados por critérios de qualificação educacional. Isto aumentaria a porcentagem da população de idade de 18 a 24 anos nesse nível de ensino, contribuiria para melhorar a qualidade da educação básica (embora não seja suficiente), adequaria a dispersão da relação de vagas entre as instituições privadas e as públicas. Os dados do INEP/2006 apontam que dos $9 \%$ dessa população, apenas $2 \%$ estão em instituições públicas.

Para nós, o anteprojeto se alinha a uma direção neoliberal quando apresenta a autonomia das instituições públicas da educação superior para "gerir recursos financeiros e patrimonias próprios, recebidos em doação ou gerados através de suas atividades finalísticas" (Anteprojeto, art. 21, item III), levando com isso as instituições públicas a diversificarem suas fontes de financiamento. Esta é uma forma sutil de privatização das instituições públicas, por meio da venda de serviços e busca de recursos junto ao mercado e da implementação de uma gestão político-empresarial. É também uma forma das instituições responderem ao objetivo explícito de "atenderem às demandas de sua região" previsto no anteprojeto. Essa relação poderá forçar a passagem da necessária autonomia universitária para a heteronomia que, na conceituação de Sguissardi (2003, p. 20), "é a subordinação a uma ordem imposta por agentes externos" enquanto a autonomia é "a capacidade de autodeterminação, independência e liberdade".

Acreditamos ainda que a autonomia didático-científica da universidade possa também sofrer um revés se a universidade for realmente solicitada a ter um engajamento maior com os interesses de grupos sociais, como prevê 0 anteprojeto quando afirma "o atendimento da universidade a demandas específicas de grupos sociais". O objetivo é o de atribuir função social às atividades das instituições. Embora à primeira vista pareça um princípio democrático, é essencialmente autoritário e apresenta uma intervenção do Estado no contexto da educação superior, colocando-o com papel de regulação, coerção e controle das políticas de expansão das vagas, do direcionamento das pesquisas, da abertura de cursos e dos currículos, tendo como critério a da taxa de retorno "social" dos investimentos públicos como é estipulado na afirmação: "autonomia sem avaliação coloca a universidade num isolamento contraditório com sua vocação regional ou nacional, apartando-a de seu entorno social" (p. 9).

Conforme afiram Boaventura Santos (2006, p. A3), há que nos prepararmos para saber viver na contradição de uma sociedade multicultural onde 
proposta de ações afirmativas reivindica o direito dos afro-descendentes de serem iguais quando a diferença os inferioriza e o direito de serem diferentes quando a igualdade os descaracteriza. As políticas sociorraciais que estão se institucionalizando por meio desse projeto de reforma da educação superior têm por base a incorporação desse princípio dentro e fora das instituições de educação superior.

Embora afirmando, como acima o fiz, que a forma de implementar as ações afirmativas sociorraciais reservando metade das escassas vagas atuais seja uma política tosca e apenas demagógica e denunciando que há a necessidade de um aumento significativo dessas vagas e uma efetiva melhora na qualidade do ensino básico, vejo que a política de ação afirmativa, da forma como está sendo pensada, detende a se perpetuar não mais como política de ação afirmativa, mas como política de ascensão social. Se as condições econômicas do país não se alterarem, não se alteram as necessidades do atendimento a esse grupo sociorracial.

Medidas equivocadas: Em anos de luta pelo não autoritarismo, pela não centralização das decisões educacionais em políticas de cabresto, aceitamos, como valor democrático, a Lei n.. 10.639, que torna obrigatório o ensino de história afro-brasileira nas escolas, no sentido de valorizar a contribuição dos imigrantes africanos e seus descendentes à cultura e à economia brasileira. É uma visão míope se estiver defendendo o multiculturalismo, pois nada fala das outras culturas que também contribuíram para a cultura e a economia brasileira - cultura amarela (o Brasil tem a maior colônia de japoneses do mundo), a cultura sírio-libanesa, a cultura italiana, etc.

Segundo dados da Secretaria Especial de Políticas de Promoção da Igualdade Racial (SEPPIR-2006), um orçamento de $\mathrm{R} \$ 2$ milhões anuais está designado no Plano Plurianual para a implantação da Política Nacional de Saúde da População Negra. Nada fala de uma política sociorracial, onde todos os pobres seriam incluídos. É uma política de inclusão racial apenas. É uma política de combate racial como se a rede de assistência à saúde tivesse implementado uma exclusão de atendimentos à população negra. Outra política do apartheid racial brasileiro é o Projeto Afroatitude, que em 2005 e 2006 concedeu 1050 bolsas de Iniciação Científica ${ }^{6}$ a estudantes negros de 11 universidades públicas para pesquisas sobre Aids e saúde da população negra. São políticas de igualdade racial entendendo como raça apenas o negro. Até o Estatuto da Igualdade Racial, discutido por um grupo interministerial, composto por vários órgãos do governo e coordenado pela SEPPIR e pela Casa Civil, aprovado no Senado em 2005, traz em seus capítulos temas como: pes-

6 Dados encontrados no site da SEPPIR da Presidência da República (Casa Civil). www.planalto.gov.br/seppir/ 
quisa e formas de prevenção e combate de doenças prevalecentes na população negra, direito à liberdade religiosa e de culto às religiões afro-brasileiras, inclusão no mercado de trabalho por meio de contratação preferencial de profissionais negros na administração pública, entre outros itens. Tais políticas estão efetivando uma divisão racial e não a superação dos atuais desníveis socioeconômicos onde estão tanto negros como não negros. O que tinha 0 caráter de ações afirmativas está sendo elevado ao patamar de políticas de Estado.

\section{Referências}

CARVALHO, M.A.; CAMPOS, M.R.M. A educação nas constituições brasileiras. São Paulo: Pontes, 1999.

FLEXNER, Abraham. Universities: english, german and american. New York: Oxford University Press, 1930.

GENRO, T. A reforma da educação superior no Brasil. In: SEMINÁRIO INTERNACIONAL, REFORMA E AVALIAÇÃO DA EDUCAÇÃO SUPERIOR: TENDÊNCIAS NA EUROPA E NA AMÉRICA LATINA. Brasília: INEP, 2005.

INEP - Boletim Informativo, v. 4, n. 130, mar. 2006.

INEP- Exame Nacional de Cursos - ENC. Disponível em: http:// www.inep.gov.br/enc/. Acessado em: 04 maio 2006.

MEC, 2005 - Informativo MEC - Edição Extra. Reforma Universitária, jul. 2005.

NEWMAN, John Henry C. The idea of university. New York: Image, 1959.

SCHWARTZMAN, S. As razões da reforma universitária. Revista Ciência Hoje, v. 36, p. 18-23, abr. 2005.

SERRANO, J. Atcon e a universidade brasileira. Rio de Janeiro: TECHINE, 1974.

SGUISSARDI V. Diferenciação e diversidade: marcas das políticas de educação superior no final do século. In: SGUISSARDI, V. (org.). Educação superior: velhos e novos desafios. São Paulo: Xamã, 2000. 